\title{
Cyanide Production and Degradation during Growth of the Snow Mould Fungus
}

\author{
By ALAN W. BUNCH AND CHRISTOPHER J. KNOWLES \\ Biological Laboratory, University of Kent, Canterbury, Kent CT2 $7 \mathrm{NJ}$
}

(Received 23 April 1979; revised 26 June 1979)

\begin{abstract}
Isolate $\mathrm{W}_{2}$ of the snow mould basidiomycete produced cyanide only at the start of the stationary phase when it was grown in shake cultures on a glucose-containing synthetic medium in which growth stopped because of glucose depletion. Cyanogenesis was stimulated by inclusion of glycine in the medium, but the presence of methionine in addition to glycine caused little further cyanide formation. Addition of cyclic AMP to the medium had no effect on the time of production or the concentration of cyanide formed. Cultures that contained excess glucose at the start of the stationary phase also produced cyanide. Cultures which contained acetate as the carbon source formed cyanide during growth and in the stationary phase; cyanogenesis was again stimulated by glycine. In cultures containing glucose, $\left[1-{ }^{14} \mathrm{C}\right]$ glycine was converted to ${ }^{14} \mathrm{CO}_{2}$ during both the growth and stationary phases, whereas $\left[2{ }^{14} \mathrm{C}\right]$ glycine was the precursor of $\left[{ }^{14} \mathrm{C}\right]$ cyanide only at the start of the stationary phase. Very little of the cyanohydrins of glyoxylic acid or pyruvic acid were formed. Cyanide was converted to $\mathrm{CO}_{2}$ as the major detoxication product; there was little formation of alanine, $\beta$-cyanoalanine, glutamate, formamide, or aspartate plus asparagine.
\end{abstract}

\section{INTRODUCTION}

An unidentified, psychrophilic basidiomycete is responsible for winter crown rot or snow mould disease of alfalfa and other forage plants (Cormack, 1948; Lebeau \& Dickson, 1953, 1955). The disease is caused by excretion of a $\beta$-glucosidase by the fungus into the plant tissue, causing release of cyanide from the cyanogenic glucosides of the host (Colotelo \& Ward, 1961 ; Lebeau, 1966).

Some isolates of the snow mould fungus are cyanogenic, producing cyanide in pure cultures (Lebeau \& Dickson, 1953, 1955; Ward et al., 1961; Ward \& Lebeau, 1962). However, the role of cyanogenesis by the fungus in the aetiology of the snow mould disease is not clear, since acyanogenic isolates are also pathogenic (Ward et al., 1961). Inclusion of glycine in the medium for cultures of isolate $\mathrm{W}_{2}$ of the fungus stimulates cyanogenesis (Ward \& Thorn, 1966; Ward et al., 1971, 1977). The cyanide carbon and nitrogen are derived from the glycine methylene and amine groups, respectively, with retention of the $\mathrm{C}-\mathrm{N}$ bond during the conversion (Ward et al., 1977). Unstable cyanogens, with properties of the cyanohydrins of glyoxylic acid and pyruvic acid, have been isolated from the snow mould. Despite the ready non-enzymic reaction of cyanide with keto groups, it has been suggested that these compounds may be formed as precursors of cyanide by the fungus (Ward, 1964; Tapper \& MacDonald, 1974).

Cyanide-producing micro-organisms are able to assimilate or detoxify cyanide by a variety of pathways (Knowles, 1976). Strobel $(1964,1966,1967)$ has claimed that the snow mould fungus incorporates cyanide into acetaldehyde and succinate semialdehyde to form alanine and glutamic acid, respectively, but the radio-labelling data suggest the extent of fixation by these routes is extremely low. 
It is the aim of the work presented in this paper to investigate further the conditions for cyanide production by the snow mould fungus growing in shake cultures, and the relationship between formation and degradation of cyanide.

\section{METHODS}

Growth of the snow mould fungus. Isolate $\mathrm{W}_{2}$ of the snow mould basidiomycete (Ward et al., 1961) was provided by Dr E. W. B. Ward. It was grown in shake cultures in the defined medium described by Ward \& Thorn (1966) except that the carbon source was either $10 \mathrm{~mm}$-glucose or $30 \mathrm{~mm}$-acetate. Vitamins and, where appropriate, amino acids were added to the medium following filter-sterilization. Conical flasks $(250 \mathrm{ml}$, with latex foam stoppers) containing $50 \mathrm{ml}$ medium were incubated at $15^{\circ} \mathrm{C}$ in an orbital shaker at $275 \mathrm{rev}$. $\mathrm{min}^{-1}$. Inocula were prepared by blending [in an Ultra-Turrax homogenizer (Janke u. Kunkel KG, Staufen i. Breisgau)] still cultures grown on a malt extract/yeast extract/glucose medium (Ward \& Colotelo, 1960); $2 \mathrm{mg}$ dry wt fungus was added to each shake flask. Growth was measured from the dry weight of complete $50 \mathrm{ml}$ shake cultures harvested at different times after inoculation (Ward \& Colotelo, 1960). Glucose was measured by the glucose oxidase method (Niven et al., 1977).

Determination of cyanide production. Cyanide formed during growth was measured in two ways. Cyanide present in the growth medium was assayed by the method of Epstein (1947). Loss of volatile cyanide from cultures was determined by using flasks fitted with a centre well containing picric acid reagent modified from that described by Skowronski \& Strobel (1969) by omitting the $\mathrm{NaOH}$ from the $\mathrm{Na}_{2} \mathrm{CO}_{3} /$ picric acid/NaOH reagent. Measurement of trapped cyanide was made at various times during growth by adding filter-sterilized picrate to the centre well and incubating the stoppered flasks for 1 to $5 \mathrm{~h}$. The rate at which cyanide was trapped was recorded as $\mu \mathrm{mol} \mathrm{h}^{-1}$.

Metabclism of $K^{14} \mathrm{CN}$. The ability of the snow mould fungus to metabolize cyanide was determined by growth for various periods, as described above, followed by transfer of the culture to flasks fitted with centre wells; the flasks were stoppered after addition of $1 \mathrm{ml} 4 \mathrm{M}-\mathrm{KOH}$ to the centre well and $\mathrm{K}^{14} \mathrm{CN}(2 \mu \mathrm{Ci}$; $59.3 \mathrm{mCi} \mathrm{mmol}^{-1}$ ) to the culture. Incubation was for at least $24 \mathrm{~h}$ and the cultures were then assayed for the products of cyanide metabolism.

Radioactive $\mathrm{CO}_{2}$ in the growth medium and centre well was measured by precipitation with saturated barium hydroxide solution. The precipitate was collected on a $0.45 \mu \mathrm{m}$ (pore size) filter which was then placed in a small flask fitted with a centre well; $0.5 \mathrm{ml}$ phenethylamine and a filter paper strip $(1 \times 4 \mathrm{~cm})$ were added to the centre well, and the flask was stoppered with a serum cap. $\mathrm{CO}_{2}$ was released by injection of $1 \mathrm{ml} 6 \mathrm{M}-\mathrm{HNO}_{3}$ and agitation of the flask for $45 \mathrm{~min}$. The radioactivity in the phenethylamine and the filt $0 \cdot(\omega 01 \%(\mathrm{w} / \mathrm{v})$ 1,4-di-2-(5-phenyloxazolyl)benzene in toluene.

Radioactive cyanide trapped in the centre well was recorded after removal of ${ }^{14} \mathrm{CO}_{2}$ by neutralizing the $\mathrm{KOH}$ with $4 \mathrm{M}-\mathrm{HCl}$ and counting in $5 \mathrm{ml}$ phase combining system (PCS)-scintillation fluid. After subtraction of the counts due to other compounds, as described below, the counts due to $\left[{ }^{14} \mathrm{C}\right]$ cyanide remaining in the medium could be obtained.

Radioactivity taken up by the fungus was measured after centrifuging and washing the cells twice in fresh growth medium, minus the carbon and nitrogen sources, at $1500 \mathrm{~g}$ in a bench centrifuge, followed by disruption of the cells by two passages at $55 \mathrm{MPa}$ through a French press. Cells and debris were removed by centrifugation at $1500 \mathrm{~g}$. The growth medium and $1500 \mathrm{~g}$ supernatant of the ruptured cells were chromatographed in butanol/acetic acid/pyridine/water (100:20:10:30, by vol.) using Eastman cellulose thin-layer chromatography (t.l.c.) plates, together with appropriate standards. The radioactivity in each spot was measured by scraping from the plate into PCS scintillation fluid.

Metabclism of $\left[{ }^{14} \mathrm{C}\right] g l y c i n e$. Cultures were grown in the presence of either $\left[1-{ }^{14} \mathrm{C}\right] \mathrm{glycine}$ or $\left[2-{ }^{14} \mathrm{C}\right] \mathrm{glycine}$ $\left(10 \mu \mathrm{Ci}\right.$ per $50 \mathrm{ml}$ culture; 56 and $54 \mathrm{mCi} \mathrm{mmol}^{-1}$, respectively) in a flask fitted with a centre well. After a set period, $1 \mathrm{ml} 4 \mathrm{M}-\mathrm{KOH}$ was added to the centre well. The flask was stoppered and incubated for $24 \mathrm{~h}$, after which $\mathrm{H}^{14} \mathrm{CN}$ and ${ }^{14} \mathrm{CO}_{2}$ production were measured as described above. The amount and distribution of radioactivity taken up by the fungus was determined after disruption of the cells followed by chromatography in butanol/acetate/dimethylamine/water (10:10:2:5, by vol.) using Eastman cellulose t.l.c. plates. The growth medium was similarly treated.

Materials. $\left[1-^{-14} \mathrm{C}\right]$ Glycine $\left(56 \mathrm{mCi} \mathrm{mmol}{ }^{-1}\right), \quad\left[2-{ }^{14} \mathrm{C}\right]$ glycine $\left(54 \mathrm{mCi} \mathrm{mmol}^{-1}\right)$ and $\mathrm{K}^{14} \mathrm{CN}(59 \cdot 3 \mathrm{mCi}$ $\mathrm{mmol}^{-1}$ ) were obtained from The Radiochemical Centre, Amersham, and PCS from Amersham Corp., Arlington Heights, Ill., U.S.A. Radio-labelled glycine was checked for purity by t.l.c. in butanol/water/ acetic acid (120:50:30, by vol.). Radio-labelled cyanide was checked for purity by t.l.c. in butanol saturated with water, to determine formamide and formate content (Oró \& Kiball, 1962). Cyclic AMP was obtained from Sigma. Wherever possible, all other reagents were of analytical grade; glass-distilled water was used throughout. 

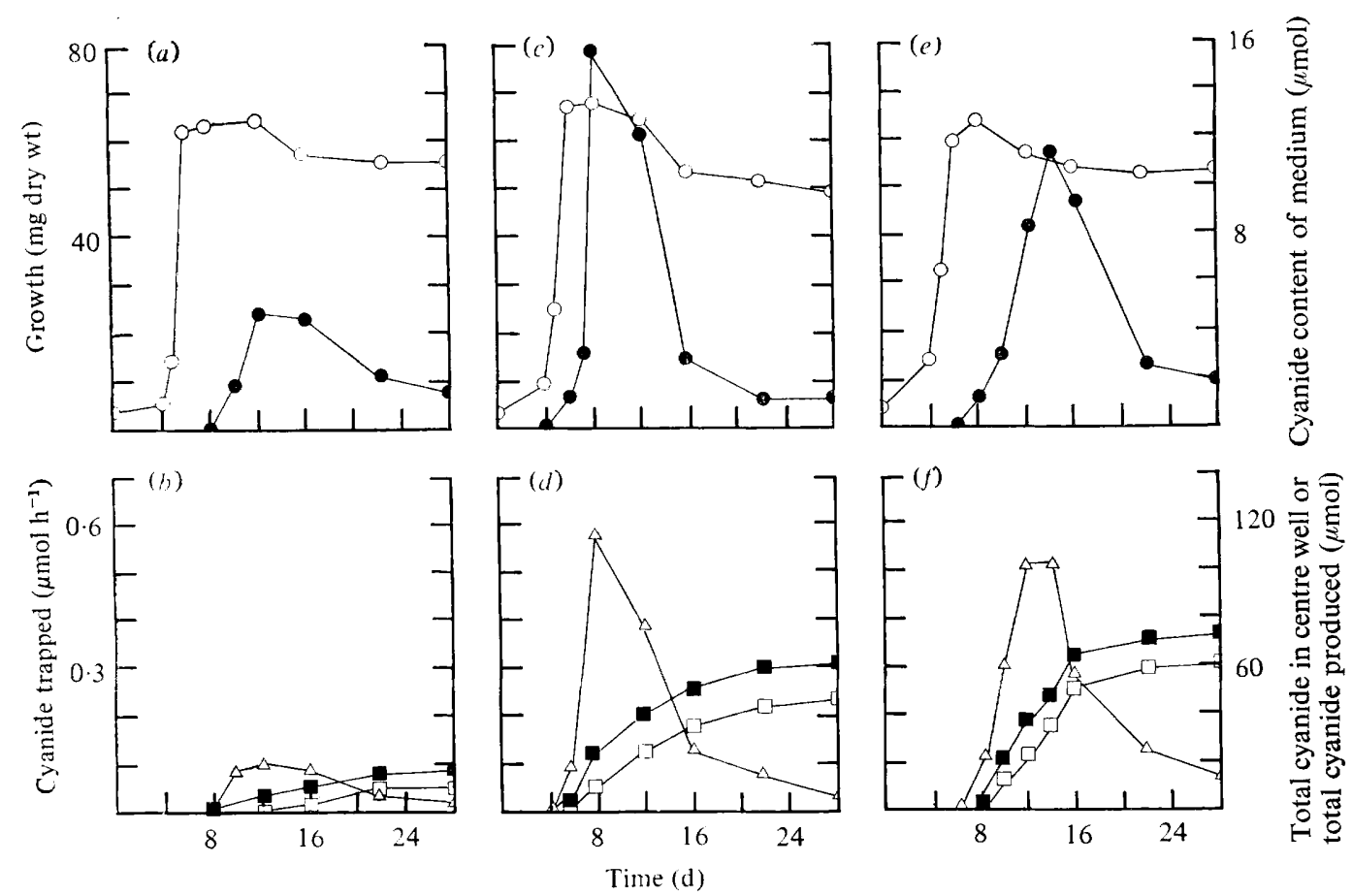

Fig. 1. Experiments with glucose: growth and cyanide production by the snow mould fungus in a mineral salts medium containing $10 \mathrm{~mm}$-glucose $(a, b), 10 \mathrm{~mm}$-glucose plus $10 \mathrm{~mm}$-glycine $(c, d)$ or $10 \mathrm{~mm}$-glucose plus $10 \mathrm{~mm}$-glycine and $10 \mathrm{~mm}$-methionine $(e, f)$. Growth $(O)$, cyanide content of growth medium ( $)$, rate at which cyanide was trapped in the centre well $(\triangle)$, total cyanide trapped in the centre well $(\square)$ and total cyanide produced ( $\square$ ). All results are for $50 \mathrm{ml}$ cultures.

\section{RESULTS}

Figure $1(a, b)$ shows cyanide production by a shake culture of the snow mould basidiomycete grown in a mineral salts medium containing $10 \mathrm{~mm}$-glucose and $15 \mathrm{~mm}-\mathrm{L}$ asparagine as the carbon and nitrogen sources, respectively. Growth stopped when glucose was depleted. Because of the volatility of cyanide, it was found only at low concentrations in the medium (Fig. 1a). The cyanide lost was trapped in alkaline picrate reagent in the centre well of the growth flask and assayed (Fig. 1b). Because the cyanide trapped was measured regularly, the period of active cyanogenesis could be determined. There was no cyanogenesis until after growth had finished, and cyanide production was maximal before autolysis occurred. The total cyanide produced was $18 \mu \mathrm{mol}$ from the $50 \mathrm{ml}$ culture.

When $10 \mathrm{~mm}$-glycine was added to the medium containing glucose there was no stimulation of growth, but the total cyanide produced increased to $61 \mu \mathrm{mol}$ per $50 \mathrm{ml}$ culture (Fig. $1 c, d$ ). The period of active cyanogenesis again occurred after growth had finished but before autolysis. Addition of L-methionine (final concentration $10 \mathrm{~mm}$ ) to the medium containing glucose and glycine caused only a small further stimulation of cyanogenesis (to $66 \mu \mathrm{mol}$ per $50 \mathrm{ml}$ culture), but the appearance of cyanide was delayed by 3 to $4 \mathrm{~d}$ (Fig. $1 e, f$ ). Lower concentrations of methionine had a lesser effect on the delay in cyanogenesis, whereas higher concentrations inhibited growth.

The optimal concentration of glycine required for cyanogenesis by glucose-containing cultures was $10 \mathrm{~mm}$. With higher concentrations of glycine, less cyanide was formed (results not shown). Variation of the medium phosphate ( 8 to $200 \mathrm{mM}$ ) or $\mathrm{Fe}^{2+}$ (3 to $200 \mu \mathrm{M}$, as $\mathrm{FeSO}_{4}$ ) concentrations had little effect on the extent of cyanogenesis or growth. Addition of 

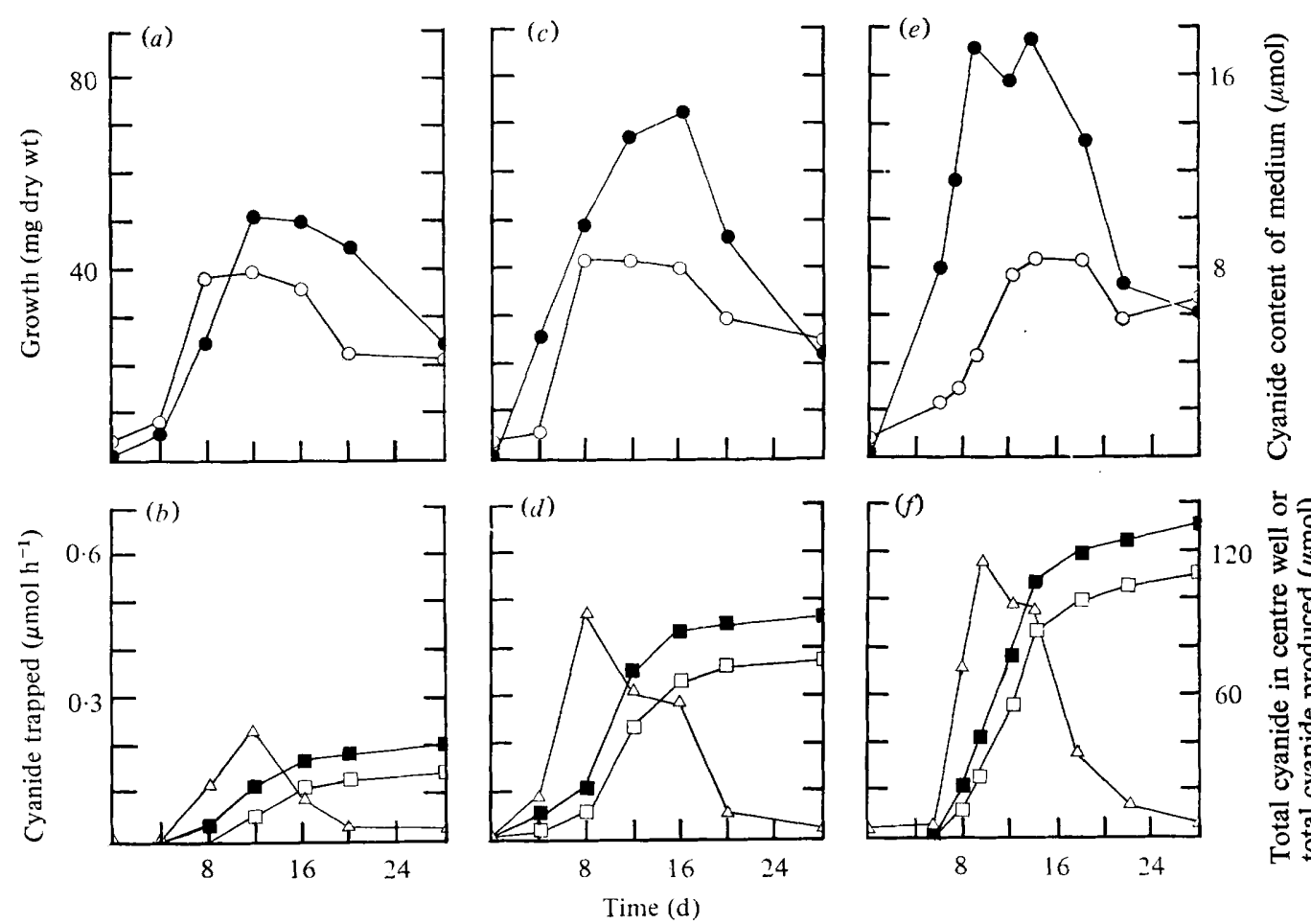

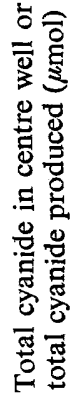

Fig. 2. Experiments with acetate: growth and cyanide production by the snow mould fungus in a mineral salts medium containing $30 \mathrm{~mm}$-acetate $(a, b), 30 \mathrm{~mm}$-acetate plus $10 \mathrm{~mm}$-glycine $(c, d)$ or $30 \mathrm{~mm}$-acetate plus $10 \mathrm{~mm}$-glycine and $10 \mathrm{~mm}$-methionine $(e, f)$. Symbols as in Fig. 1. All results are for $50 \mathrm{ml}$ cultures.

5 mM-cyclic AMP to the medium had no effect on the amount of cyanide produced or on its time of appearance. Increasing the medium glucose concentration to $83 \mathrm{~mm}$, as previously used by Ward \& Lebeau (1962) and Ward \& Thorn (1966), increased the growth yield to $310 \mathrm{mg}$ dry wt mycelium per $50 \mathrm{ml}$ culture and, in the presence of $0 \cdot 1 \mathrm{M}$-glycine, the cyanide yield was $27.6 \mu \mathrm{mol}$. Growth in the presence of $83 \mathrm{~mm}$-glucose was limited by asparagine depletion and there was residual glucose in the medium in the stationary phase.

The stimulatory effect of glycine on cultures containing $10 \mathrm{~mm}$-glucose occurred when it was added up to $7 \mathrm{~d}$ after inoculation. Later addition of glycine resulted in lower yields of cyanide.

The growth yield for cultures containing $30 \mathrm{~mm}$-acetate was lower than for cultures containing $10 \mathrm{~mm}$-glucose (Fig. 2a). Glycine or glycine plus L-methionine again had no effect on growth (Fig. $2 c, e$ ). The amount of cyanide produced in the cultures containing glycine was higher with acetate as the carbon source $(90 \mu \mathrm{mol}$ per $50 \mathrm{ml}$ culture) than for growth in the presence of glucose and glycine (Fig. $2 d$ and $1 d$ ). The further addition of L-methionine (Fig. $2 f$ ) caused only a slight further stimulation of cyanogenesis to $130 \mu \mathrm{mol}$ per $50 \mathrm{ml}$ culture. Cyanide was produced during active growth in the medium containing acetate, either with or without glycine and glycine plus L-methionine, rather than at the start of the stationary phase, as found for glucose-grown cultures.

Under all growth conditions the $\mathrm{pH}$ of the growth medium changed from $\mathrm{pH} 6 \cdot 0$ to about $\mathrm{pH} 8.0$; no decrease in $\mathrm{pH}$ was ever noted.

Cultures were grown in medium containing $10 \mathrm{~mm}$-glucose plus either $10 \mathrm{~mm}-\left[1-{ }^{14} \mathrm{C}\right]$ glycine or $10 \mathrm{~mm}-\left[2-{ }^{14} \mathrm{C}\right]$ glycine (Fig. 3 ). The $\left[2-{ }^{14} \mathrm{C}\right]$ glycine was converted into $\left[{ }^{14} \mathrm{C}\right]$ cyanide at the start of the stationary phase, as expected from the results in Fig. $1(c, d)$. The ${ }^{14} \mathrm{C}$ from 


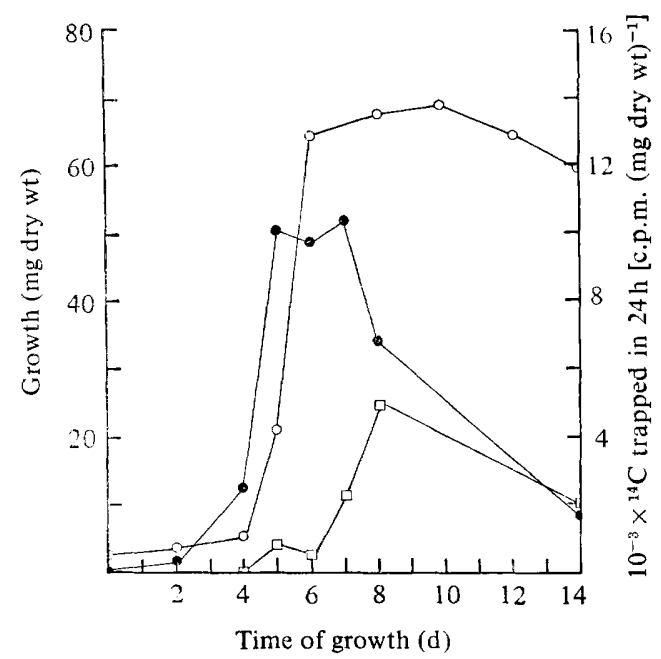

Fig. 3

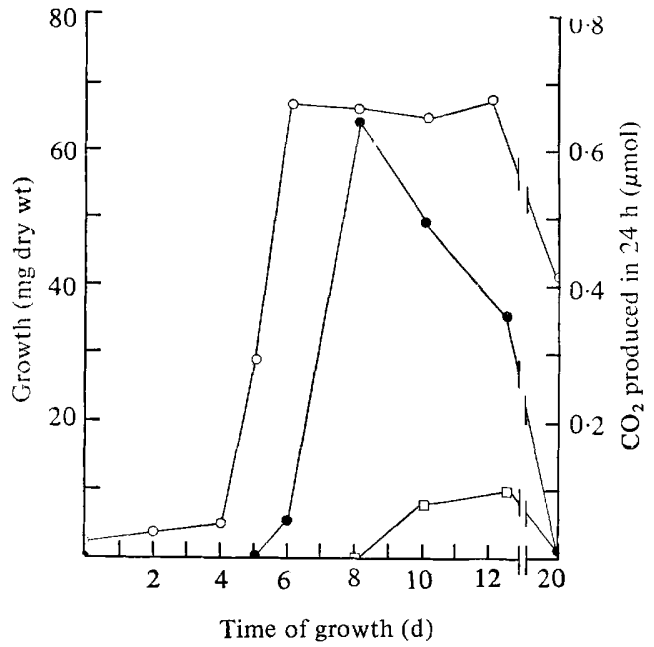

Fig. 4

Fig. 3. Metabolism of $\left[1-{ }^{14} \mathrm{C}\right]$ glycine or $\left[2-{ }^{14} \mathrm{C}\right] \mathrm{glycine}(10 \mu \mathrm{Ci} ; 500 \mu \mathrm{mol})$ during growth of the snow mould fungus in medium $(50 \mathrm{ml})$ containing $10 \mathrm{~mm}$-glucose plus $10 \mathrm{~mm}$-glycine. Growth $(\bigcirc)$, ${ }^{14} \mathrm{CO}_{2}$ production from $\left[1-{ }^{14} \mathrm{C}\right]$ glycine $(O)$ and $\mathrm{H}^{14} \mathrm{CN}$ production from $\left[2-{ }^{14} \mathrm{C}\right] \mathrm{glycine}(\square)$; each point represents the total ${ }^{14} \mathrm{C}$ trapped during the previous $24 \mathrm{~h}$.

Fig. 4. Production of ${ }^{14} \mathrm{CO}_{4}$ from $\left[{ }^{14} \mathrm{C}\right]$ cyanide by cultures of the snow mould fungus grown in a medium containing $10 \mathrm{~mm}$-glucose or $10 \mathrm{~mm}$-glucose plus $10 \mathrm{~mm}$-glycine. Growth was similar under both conditions, so only growth on glucose alone is shown $(\mathrm{O}) \cdot{ }^{14} \mathrm{CO}_{2}$ trapped during growth on glucose $(\square)$ or glucose plus glycine $(\bigcirc)$ was recorded after incubation with $\mathrm{K}^{14} \mathrm{CN}(2 \mu \mathrm{Ci}$; $59 \mathrm{mCi} \mathrm{mmol}^{-1}$ ) for $24 \mathrm{~h}$ prior to the time shown. All results are for $50 \mathrm{ml}$ cultures.

$\left[1-{ }^{14} \mathrm{C}\right]$ glycine was detected in $\mathrm{CO}_{2}$ both during and after growth. Glycine was therefore mainly converted into $\mathrm{CO}_{2}$ and some other product, derived from the methylene group, during growth, and into $\mathrm{CO}_{2}$ plus cyanide during the stationary phase.

To determine the products of cyanide degradation, cultures were grown in medium containing glucose and a low concentration of $\left[{ }^{14} \mathrm{C}\right]$ cyanide was added at various times, followed by analysis of the products $24 \mathrm{~h}$ later. Table 1 shows the results of one such experiment. Unconverted cyanide (69 to $82 \%$ of the total) was recovered from the medium and the $\mathrm{NaOH}$ trap. Of the rest (18 to $31 \%$ of the total), $9 \%$, or less, of the ${ }^{14} \mathrm{C}$ was detected in the cells. The major conversion product was ${ }^{14} \mathrm{CO}_{2}$. Zero or negligible ${ }^{14} \mathrm{C}$ was found in possible assimilatory products (L-alanine, L-glutamate, L-aspartate plus L-asparagine, $\beta$-cyanoalanine and total protein). Incubation with $\left[{ }^{14} \mathrm{C}\right]$ cyanide for longer periods resulted in an increasingly greater conversion to ${ }^{14} \mathrm{CO}_{2}$.

In the experiments mentioned above no cyanohydrins of glyoxylic acid or pyruvic acid were detected. Cultures grown for 5,7 or $15 \mathrm{~d}$ were extracted with ethanol/glacial acetic acid $(95: 5, \mathrm{v} / \mathrm{v})$, separated and chromatographed as described by Tapper \& MacDonald (1974). Only traces of the cyanohydrins were detected. The cyanohydrins are unstable above pH 7 (Tapper \& MacDonald, 1974). Direct treatment of cultures with $\mathrm{NaOH}$ followed by a surplus of $\mathrm{HCl}$ did not result in an appreciable increase in the amount of free cyanide. It is concluded that little of the cyanohydrins of glyoxylic acid and pyruvic acid were present either immediately before, during or after cyanogenesis in cultures grown under these conditions.

The extent of conversion of cyanide to $\mathrm{CO}_{2}$ in cultures grown in the medium containing glucose plus glycine was measured during $24 \mathrm{~h}$ periods following addition of $\left[{ }^{14} \mathrm{C}\right]$ cyanide at various times to growth flasks (Fig. 4). The rate of conversion to $\mathrm{CO}_{2}$ correlated with the 
Table 1. Distribution of ${ }^{14} C$ in products formed from $K^{14} C N$ by the snow mould fungus

$\mathrm{K}^{14} \mathrm{CN}$ was added to a culture which had been grown in medium containing $10 \mathrm{~mm}$-glucose for $12 \mathrm{~h}$, and the distribution of ${ }^{14} \mathrm{C}$ was measured $24 \mathrm{~h}$ later. Values are the ranges of results from five independent growth flasks. The total percentage recovery of counts was 81 to $93 \%$.

$\begin{array}{lc} & \begin{array}{c}\text { Percentage of } \\ { }^{14} \mathrm{C} \text { recovered }\end{array} \\ \text { Residual cyanide in growth medium } & 44-51 \\ \text { Trapped cyanide in centre well } & 25-31 \\ \text { Taken up by fungus } & 6-9 \\ \text { Protein etc. } & 2-4 \\ \text { Carbon dioxide } & 15-19 \\ \text { Alanine } & 0 \\ \text { Glutamate } & 0 \\ \beta \text {-Cyanoalanine } & 0 \\ \text { Asparagine/aspartate } & 0 \\ \text { Formamide } & 0\end{array}$

rate of cyanide production and was optimal about $8 \mathrm{~d}$ after inoculation. Again the major product of cyanide degradation was $\mathrm{CO}_{2}$, and only small amounts of ${ }^{14} \mathrm{C}$ were recovered in the possible assimilatory products shown in Table 1. Cultures grown in medium containing glucose or glucose plus glycine for 1 to $28 \mathrm{~d}$ did not show an increased ability to convert cyanide to any other possible assimilatory product.

\section{DISCUSSION}

The production of cyanide from glycine by the snow mould fungus occurred at the end of the growth phase (i.e. during the idiophase) when it was grown in a synthetic medium containing $10 \mathrm{~mm}$-glucose and $10 \mathrm{~mm}$-glycine. This is typical of production of secondary metabolites by micro-organisms (Drew \& Demain, 1977). Formation of cyanide from glycine during the idiophase has also been observed in cultures of cyanogenic bacteria (Castric, 1975; Rodgers \& Knowles, 1978). Synthesis of many secondary metabolites is more sensitive than growth to variations in composition of the medium, especially with respect to the content of phosphate and other ions (Drew \& Demain, 1977). Unlike cyanogenic bacteria (Meganathan \& Castric, 1977; Rodgers \& Knowles, 1978), cyanide production by the snow mould fungus was insensitive to variations in the phosphate and $\mathrm{Fe}^{2+}$ content of the medium. A further difference between the bacterial and fungal systems is the massive stimulation of cyanogenesis from glycine by methionine in bacteria (Michaels \& Corpe, 1965; Wissing, 1968; Castric, 1975; Rodgers \& Knowles, 1978).

It has been suggested that carbon catabolite repression may affect secondary metabolite production (Demain et al., 1979). Glucose is often a key growth substrate causing catabolite repression in many micro-organisms (Pastan \& Adhya, 1976; Demain et al., 1979). Thus the observation that cyanide was not produced from glycine by cultures of the snow mould fungus grown on $10 \mathrm{~mm}$-glucose until the glucose was depleted from the medium, but that when grown on $30 \mathrm{~mm}$-acetate cyanide was produced during growth, suggested that the synthesis of cyanide may have been prevented due to catabolite repression by glucose. However, addition of cyclic AMP to the medium had no effect on cyanogenesis by cultures grown on $10 \mathrm{~mm}$-glucose. Moreover, cultures containing $83 \mathrm{~mm}$-glucose, in which excess glucose was present in the stationary phase, also produced cyanide from glycine at the start of this phase.

In contrast to our results for cultures grown in the synthetic medium containing glucose, Ward \& Lebeau (1962) suggested that free cyanide was produced after the onset of autolysis when the fungus was grown in shake cultures in a similar medium but containing $83 \mathrm{~mm}-$ 
glucose. Ward \& Thorn (1966), using still cultures containing $83 \mathrm{~mm}$-glucose and $18 \mathrm{~mm}$ glycine, showed that cyanogenesis occurred during growth. However, the latter workers removed cyanide from the cultures by steam distillation, thus assaying the total of free and combined cyanide. A significant proportion of the cyanide in the latter experiments could have been due to the presence of an unstable cyanohydrin (Ward, 1964), which had the properties of the cyanohydrins of glyoxylic acid and pyruvic acid (Tapper \& MacDonald, 1974). We have observed only traces of these compounds. This does not infer that they are not derivatives of glycine that act as precursors of cyanide since, if they do have such a role, their relative concentrations will be determined by which reaction in the process is the rate-limiting step. It is only possible to speculate on the differences between our results and those of Ward \& Thorn (1966). One possibility is that in our experiments the lower total growth (limited by having only $10 \mathrm{~mm}$-glucose in the medium) and a higher rate of aeration prevented build-up of fermentation products and hence non-enzymic formation of the cyanohydrins.

The conversion of the carboxyl group of exogenous glycine to $\mathrm{CO}_{2}$ prior to synthesis of cyanide from the methylene group in glucose-containing cultures indicates that the methylene group was utilized for some other product(s) during growth. For example, the $\mathrm{C}_{1}$ fragment could have been used, via the tetrahydrofolic acid pool, in the production of purines, histidine, methionine etc. When demand for synthesis of these metabolites decreased at the end of growth, glycine catabolism could be switched to cyanide formation.

The major product of cyanide catabolism was $\mathrm{CO}_{2}$. There was little formation of the amino acid derivatives of various aldehydes, previously suggested by Strobel $(1964,1966$, $1967)$ to be products of cyanide assimilation. Fry \& Millar (1972) have reported that Stemphylium loti forms an enzyme that hydrolyses cyanide to formamide (formamide hydrolase or cyanide hydratase). The snow mould fungus could have formed a similar enzyme, degrading the formamide produced to $\mathrm{CO}_{2}$ via an amidase and formate dehydrogenase. Alternatively, conversion to formate could have been direct, by a nitrilase (Knowles, 1976). The presence of such an enzyme or system in the snow mould fungus is interesting as it could form the basis of a sensitive and specific system for assay of cyanide, or for detoxication of cyanide as a poison or for removal of cyanide wastes. In addition, there have been several reports of micro-organisms able to grow on cyanide (Knowles, 1976). A possible pathway of cyanide utilization in these organisms could be its conversion to formamide or formate and assimilation via a normal methylotrophic metabolic pathway (Quayle, 1972).

This work was supported by the Science Research Council via grant no. GR/A/11543 to C.J.K. and a research studentship to A.W.B. Mrs P. A. Collins provided excellent technical assistance. We thank Dr P. B. Rodgers for helpful discussions and Dr E. W. B. Ward for providing a culture of the snow mould basidiomycete.

\section{REFERENCES}

Castric, P. A. (1975). Hydrogen cyanide, a secondary metabolite of Pseudomonas aeruginosa. Canadian Journal of Microbiology 21, 613618.

Colotelo, N. \& Ward, E. W. B. (1961). $\beta$-Glycosidase activity and cyanogenesis in the susceptibility of alfalfa to winter crown rot. Nature, Londen 189, 242-243.

Cormack, M. W. (1948). Winter crown rot or snow mold of alfalfa, clovers, and grasses in Alberta. I. Occurrence, parasitism, and spread of the pathogen. Canadian Journal of Research, Section C. 26, 71-85.
Demain, A. L., Kennel, Y. M. \& Aharonowitz, Y. (1979). Carbon catabolite regulation of secondary metabolism. Symposia of the Society for General Microbiology 29, 163-185.

Drew, S. W. \& Demain, A. L. (1977). Effect of primary metabolites on secondary metabolism. Annual Review of Microbiology 31, 343-356.

EPSTEIN, J. (1947). Estimations of microquantities of cyanide. Analytical Chemistry 19, 272-274.

Fry, W. E. \& Millar, R. L. (1972). Cyanide degradation by an enzyme from Stemphylium loti. Archives of Biochemistry and Biophysics 151, 468474. 
KNowles, C. J. (1976). Microorganisms and cyanide. Bacteriological Reviews 40, 652-680.

Lebeau, J. B. (1966). Pathology of winter injured grasses and legumes in Western Canada. Crop Science 6, 23-25.

Lebeau, J. B. \& Dickson, J. G. (1953). Preliminary report on production of hydrogen cyanide by a snow mold pathogen. Phytopathology 43, 581582.

Lebeau, J. B. \& Dickson, J. G. (1955). Physiology and nature of disease development in winter crown rot of alfalfa. Phytopathology 45, 667-673.

Meganathan, R. \& Castric, P. A. (1977). The effect of inorganic phosphate on cyanogenesis by Pseudomonas aeruginosa. Archives of Microbiology 114, 51-54.

Michaels, R. \& CoRpe, W. A. (1965). Cyanide formation by Chromobacterium violaceum. Journal of Bacteriology 89, 106-112.

Niven, D. F., Collins, P. A. \& Knowles, C. J. (1977). Adenylate energy charge during batch culture of Beneckea natriegens. Journal of General Microbiology 98, 95-108.

Oró, J. \& Kiball, A. P. (1962). Synthesis of purines under possible primitive earth conditions. II. Purine intermediates from hydrogen cyanide. Archives of Biochemistry and Biophysics 96, 293-313.

Pastan, I. \& Adhya, S. (1976). Cyclic adenosine 5'-monophosphate in Escherichia coli. Bacteriological Reviews 40, 527-551.

QuAYLE, J. R. (1972). The metabolism of onecarbon compounds by micro-organisms. Advances in Microbial Physiology 7, 119-202.

Rodgers, P. B. \& KNowles, C. J. (1978). Cyanide production and degradation during growth of Chromobacterium violaceum. Journal of General Microbiology 108, 261-267.

Skowronski, B. \& Strobel, G. A. (1969). Cyanide resistance and cyanide utilisation by a strain of Bacillus pumilus. Canadian Journal of Microbiology 15, 93-98.

Strobel, G. A. (1964). Hydrocyanic acid assimil- ation by a psychrophilic basidiomycete. Canadian Journal of Biochemistry 42, 1637-1639.

Strobel, G. A. (1966). The fixation of hydrocyanic acid by a psychrophilic basidiomycete. Journal of Biological Chemistry 241, 2618-2621.

Strobel, G. A. (1967). 4-Amino-4-cyanobutyric acid as an intermediate in glutamate biosynthesis. Journal of Biological Chemistry 242, 3265-3269.

TAPPER, B. A. \& MACDonald, M. A. (1974). Cyanogenic compounds in cultures of a psychrophilic basidiomycete (snow mold). Canadian Journal of Microbiology 20, 563-566.

WARD, E. W. B. (1964). On the source of hydrogen cyanide in cultures of snow mold fungus. Canadian Journal of Botany 42, 319-327.

WARD, E. W. B. \& Colotelo, N. (1960). The importance of inoculum standardization in nutritional experiments with fungi. Canadian Journal of Microbiology 6, 545-556.

Ward, E. W. B. \& Lebeau, J. B. (1962). Autolytic production of hydrogen cyanide by certain snow mold fungi. Canadian Journal of Botany 40, 85-88.

WARd, E. W. B. \& Thorn, G. D. (1966). Evidence for the formation of $\mathrm{HCN}$ from glycine by a snow mold fungus. Canadian Journal of Botany 44, 95-104.

Ward, E. W. B., Lebeau, J. B. \& Cormack, M. W. (1961). Grouping of isolates of a low-temperature basidiomycete on the basis of cultural behaviour and pathogenicity. Canadian Journal of Botany 39, 297-306.

Ward, E. W. B., Thorn, G. D. \& Starratt, A. N. (1971). The amino acid source of HCN in cultures of a psychrophilic basidiomycete. Canadian Journal of Microbiology 17, 1061-1066.

Ward, E. W. B., Starratt, A. N. \& Robinson, J. R. (1977). Studies of the pathway of HCN formation from glycine in a psychrophilic basidiomycete. Canadian Journal of Botany 55, 2065-2069.

Wissing, F. (1968). Growth curves and pH optima for cyanide producing bacteria. Physiologia plantarum 21, 589-593. 